\title{
"How am I doing? Just ask me!" The usefulness of patient self-reported quality of life in thoracic surgery
}

\author{
Michael T. Jaklitsch, MD
}

See related article on pages 718-26.

Estimates of risk for a poor outcome after thoracotomy and lung resection are based primarily on pulmonary function tests, dyspnea scales, and measurements of cardiorespiratory reserve. Operative risks have decreased for most patients during the past 20 years for a variety of reasons, and this in turn has allowed experienced centers to offer surgical intervention for more impaired patients. Previous prohibitive benchmarks that excluded some patients from surgical intervention (such as forced expiratory volume in 1 second $<1 \mathrm{~L}$ ) are no longer considered nonoperative thresholds. ${ }^{1}$

There has been interest in gaining the participation of the patient with pulmonary impairment in this assessment of risk and baseline quality of life. After all, the patients themselves have a strong sense of how they will do with treatment. Patient estimates of performance status correlate better with symptoms than do physician estimates of performance status. ${ }^{2}$ Patient self-assessment and understanding of risk are paramount to the informed consent process, and I believe that patient self-assessment has been underutilized in surgical studies.

In this issue of the Journal, Fernando and colleagues ${ }^{3}$ report on the use of 2 self-administered quality of life tools (questionnaires) as part of a prospective, randomized control trial of sublobar lung resection for cancer versus sublobar lung resection with locally applied brachytherapy in a population with respiratory impairment. These are further data from the previously published Alliance for Clinical Trials in Oncology and American College of Surgeons Oncology Group cooperative group trial Z4032. ${ }^{4}$ This is a noteworthy contribution, because there is no comparable source of prospectively acquired quality of life data for such a high-risk group facing lung surgery. A number of interesting observations have come from this study:

1. Self-assessment questionnaires are feasible in a surgical office and in a postoperative ward. Critics of surgical

\footnotetext{
From the Department of Thoracic Surgery, Brigham \& Women's Hospital, Harvard Medical School, Boston, Mass.

Disclosures: Author has nothing to disclose with regard to commercial support.

Received for publication Nov 25, 2014; accepted for publication Nov 25, 2014; available ahead of print Jan 15, 2015.

Address for reprints: Michael T. Jaklitsch, MD, Department of Thoracic Surgery, Brigham \& Women's Hospital, Harvard Medical School, 75 Francis St, Boston, MA 02115 (E-mail: mjaklitsch@partners.org).

J Thorac Cardiovasc Surg 2015;149:663-4

$0022-5223 / \$ 36.00$

Copyright (c) 2015 by The American Association for Thoracic Surgery

http://dx.doi.org/10.1016/j.jtcvs.2014.11.068
}

self-assessment tools have claimed that they are not practical in a busy office. The SF-36 Health Survey and the University of California, San Diego dyspnea scales have a combined total of 60 questions and take less than 30 minutes to complete together. Completion rates were $98 \%$ at baseline and $83 \%$ at 3 months.

2. Repeated self-assessment questionnaires are less feasible in measuring recovery, and results are difficult to obtain after 2 years. Similar to our experience with geriatric questionnaires, this study reports decays in response rates at 1 year $(69 \%)$ and 2 years (only $50 \%$ ).

3. Patients with extreme respiratory impairment have more reduction in their physical abilities than in their mental abilities. The SF-36 Health Survey responses in this study were normalized to the general US population. The physical scores at baseline of 42.7 (with 50 representing the norm) suggest a reduction in functional status relative to the average American, whereas the mental scores were 51.1. Although this fact seems intuitively obvious, these values were not measured previously.

4. Preoperative self-assessment was unable to predict adverse events after surgery in this high-risk population. Self-assessment questionnaires have been useful in predicting adverse outcomes after chemotherapy and surgery. ${ }^{5,6}$ One potential goal of these assessments is to identify an occult weaker group of patients. Most surgeons can think of a patient who appeared strong enough for surgery before the operation but appeared vulnerable and frail soon after. The predictive value of self-assessment may be more powerful in a broader population, however, than in a selected high-risk population such as the Alliance Z4032 trial (forced expiratory volume in 1 second $<50 \%$ predicted, lung diffusing capacity for carbon monoxide $<50 \%$ predicted ${ }^{4}$ ). The amount of pulmonary impairment required to enter this trial was likely the prime determinant of morbidity.

5. Minimally invasive surgery had less impact on quality of life. With the repeated assessments as a measure of recovery, there was an increase in dyspnea at 12 months for those with larger segmental resections relative to wedges and for those treated with thoracotomy relative to video-assisted thoracoscopic surgery. There was also a modest increase in physical function 3 months after surgery relative to preoperative values in the videoassisted thoracoscopic surgery group.

This prospective study highlights some of the additional information available with self-assessment tools as well as their limitations. These tools have the potential to predict 
outcomes in certain populations but may not be as predictive as many of the more traditional studies of cardiorespiratory reserve.

Our electronically based culture is making these assessments easier to obtain. Questionnaires can be accessed through the web, even before the initial surgical consultation. In the case of geriatric assessments, the selfassessment tools frequently include measures of mood, cognitive function, falls, and social supports. Such an assessment provides the care team with a more global picture of the patient and is invaluable in making plans for after-hospital care. It also allows patients to provide their surgeons with a better picture of themselves, as people, instead of as disease cases. We have been trained to inquire about symptoms and diseases. Self-assessment tools allow our patients to tell us more completely about themselves and frequently become a springboard to discuss fears of the near future after surgery and what that might look like. They allow us to ask our patients more completely, "How are you doing?"

\section{References}

1. Bravo-Iñiguez C, Perez Martinez M, Armstrong KW, Jaklitsch MT. Surgical resection of lung cancer in the elderly. Thorac Surg Clin. 2014;24:371-81.

2. Bock M, Moore D, Hwang J, Shumay D, Lawson L, Hamolsky D, et al. The impact of an electronic health questionnaire on symptom management and behavior reporting for breast cancer survivors. Breast Cancer Res Treat. 2012; 134:1327-35.

3. Fernando HC, Landreneau RJ, Mandrekar SJ, Nichols FC, DiPetrillo TA, Meyers BF, et al. Analysis of longitudinal quality-of-life data in high-risk operable patients with lung cancer: Results from the ACOSOG Z4032 (Alliance) multicenter randomized trial. J Thorac Cardiovasc Surg. 2015;149:718-26.

4. Fernando HC, Landreneau RJ, Mandrekar SJ, Nichols FC, Hillman SL, Heron DE, et al. Impact of brachytherapy on local recurrence rates after sublobar resection: results from ACOSOG Z4032 (Alliance), a phase III randomized trial for highrisk operable non-small-cell lung cancer. J Clin Oncol. 2014;32:2456-62.

5. Hurria A, Togawa K, Mohile SG, Owusu C, Klepin HD, Gross CP, et al. Predicting chemotherapy toxicity in older adults with cancer: a prospective multicenter study. J Clin Oncol. 2011;29:3457-65.

6. Feng MA, McMillan DT, Crowell K, Muss H, Nielsen ME, Smith AB. Geriatric assessment in surgical oncology: A systematic review. J Surg Res. 2015;193:265-72. 